\title{
Mathematics and Geography with Digital-Earth
}

\author{
Durval SILVA \\ Elementary and Secondary School of Santa Maria-Beja/ Portugal ·durval.silva@agr1beja.pt
}

This contribution was double-blind reviewed as extended abstract.

\begin{abstract}
A group of Mathematics teachers from a Digital-Earth.eu partner school have come across new technologies and integrated geo-media software to teach simple daily tasks in Mathematics and Geography, within the Portuguese national curriculum. We aimed at portraying Portuguese History, namely since the discoveries in the 15th century, showing the importance of Mathematics in the invention of navigation and mapping tools until the present day, resorting to the possibilities of using this software.
\end{abstract}

\section{Introduction: Portuguese History, Geography and Mathematics}

Since the discoveries in the 15th century, Portuguese explorers have felt the need to share information about tides, winds, climate conditions, and nautical charts because, at first, the knowledge was scarce for such great adventure. It was at this time that a school for navigators was created in Sagres, in order to help overcome the unpredictability of the natural environment. This goal was ambitious and identifying the route for the first voyage to India was difficult to achieve.

At this time geographers and mathematicians worked together to solve issues such as establishing geographic position and others related to location, latitude and longitude. On many mercantile long distance voyages that took place, it was necessary to avoid shipwrecks and to ensure that the vessels would arrive safely.

Within this context, the Portuguese mathematician, Pedro Nunes (born in 1502, died in 1578) was a vital figure. His vast theoretical knowledge and his interest in accurate measurement encouraged him to create several astronomical devices and graphical methods to solve navigational problems. To tackle students' discouragement and lack of interest in a conventional teaching class which is traditionally teacher-centered, it was necessary to explore and introduce new methodologies within the classroom.

The Digital-Earth.eu project encouraged pupils and teachers in our school to work together and develop group work involving the subjects of Geography and Mathematics. Thus, teachers from these subjects came together to work out solutions to real world problems and encourage students to have an active role in building their own knowledge. Students' knowledge and scientific literacy was enhanced through the articulation of common issues in the Mathematics and Geography curricula and the outcome was a relative mind shift. 
The main goal of this paper is to present some of the good teaching practices within the subjects of Geography and Mathematics in our school, framed by the project Digitalearth.eu.

\section{The Geography and Mathematics Curriculum in Portugal}

The Portuguese national school curriculum for elementary level (equivalent to Junior or Middle Schools) is not just concerned with summing up each subject and its content. At the end of the nine-year school period, every student should have acquired a certain level of competence in areas such as Mathematics, Geography, Language, Arts and so on. In the classroom, the teachers' role is rather that of an interpreter, a decision maker and an organizer of the content, rather than a mere executor or provider of knowledge.

Like other subjects, Geography education aims to identify and improve the characteristics of a geographically competent person. Thus, the educators have to make sure that all students by the age of 15 (fifteen) have a solid general knowledge of the various geographical domains. The Geography curriculum is especially concerned with the most contemporary aspects of learning such as the education for citizenship or the involvement of students in projects, such as Digital-Earth.eu. In the Portuguese curriculum, geographical studies are closely related to history, as well as being even closer to natural sciences and mathematics.

On the other hand geography deals with issues related to citizenship and multiculturalism, among others. Geography has an undeniable role on this comprehensive and multidisciplinary approach of understanding the world and linking different domains of knowledge. Furthermore, it is even more vital if we consider its obviously relevant role on local and global projects.

The Digital-Earth.eu project has provided the possibility to link geography and mathematics with the use of geo-media tools and technologies across the curriculum. Geography needs the knowledge that mathematics provides, but mathematics needs geography to present it in the real world. This project in which our school takes part has made us all think and act differently.

Our school is located in the south of Portugal in a small city called Beja. The region has very specific conditions. Its economy is based on agriculture and services and the population density is very low.

The school is located in an area commonly characterised by poor and minority group neighbourhoods. A large number of pupils belong to these poor strata groups and there are many minority groups like gypsies and western European immigrants. The school also faces challenges with special needs students that have been integrated into the common curriculum. We believe that the participation of the school in projects with international partners is quite useful both to teachers and pupils. It will enable us to share ideas, concepts and personal experiences, enlarge the children's knowledge about real world problems and its integration of GI(S) in several subjects. It is a great tool for those who, unfortunately, do not have the opportunity to visit other countries and know other realities. It is also useful, interesting and motivating to get to know a new tool (ICT and GIS) for teaching and learning. 
Schools have today the opportunity to make use a set of tools that allow them to interact on an international scale with the other schools, sharing information, knowledge and good practices of education. The eTwinning platform (http://www.etwinning.net) is one of these tools, providing not only ways to search for partners and projects with common interest, as well as the development of new projects.

\section{How is Geo-Media Used with our Students?}

Students have been encouraged to participate in national science projects and contests using geo-media and consequently we managed to engage the whole school. We organized workshops and seminars targeted on using geo-media for students from different grades. Based on the national curriculum for Geography and Mathematics, we have taught some content using GIS (Geographic Information Systems).

Other students' projects and essays about geo-media, within the Digital-Earth.eu context, caught the attention of some national educational publishers interested in producing educational resources. On November $16^{\text {th }} 2011$ we organized a "GIS Day", sponsored by a state enterprise (EDIA). The program included debates and seminars involving students from different grades. Therefore we managed to implement the use of geo-media in Geography and Mathematics classes to 7th, 8th and 9th grade students.

\subsection{Methods and Results}

The teaching method was based on developing project work linking Geography and Mathematics.

The results showed an improvement on the competencies to design projects for Geography and Mathematics, a greater awareness on the interrelation of the contents of these two subjects, and a more positive attitude towards Mathematics and Geography.

\subsection{An Example of learning; "Terrestrial Telecommunications"}

This example aims at establishing a method to identify the most suitable places to implement the necessary infrastructures to allow the expansion of terrestrial telecommunication network coverage, promoting the sustainability of nature and reduce costs.

The class was organized into working groups (pairs) and performed a set of tasks, following the example of the teacher, requiring its help whenever needed. In general terms teachers and students explored the space and mapping through systems of geographic information and mathematical software called Geogebra (www.geogebra.org/).

The software was used to create telecom coverage zones, it also allows students to explore the impact of how a gradual expansion in space terms and time of the communication nets. The software allows a visualisation of the rapid implementation of infrastructures (telecommunication towers), with students exploring the space map through the geographic information systems and mathematics software (http://www.geogebra.org/cms/). Analysis is also possible, for instance, by lowering the telecommunication costs it will become possible to implement telecoms in many developing countries. Telecommunication costs to and from 
many developing countries are disproportionally high due to the lack of appropriate telecommunication infrastructure.

The data for these activities was obtained from "Pordata" (database of modern Portugal geoinformation) http://www.pordata.pt/en/Home.

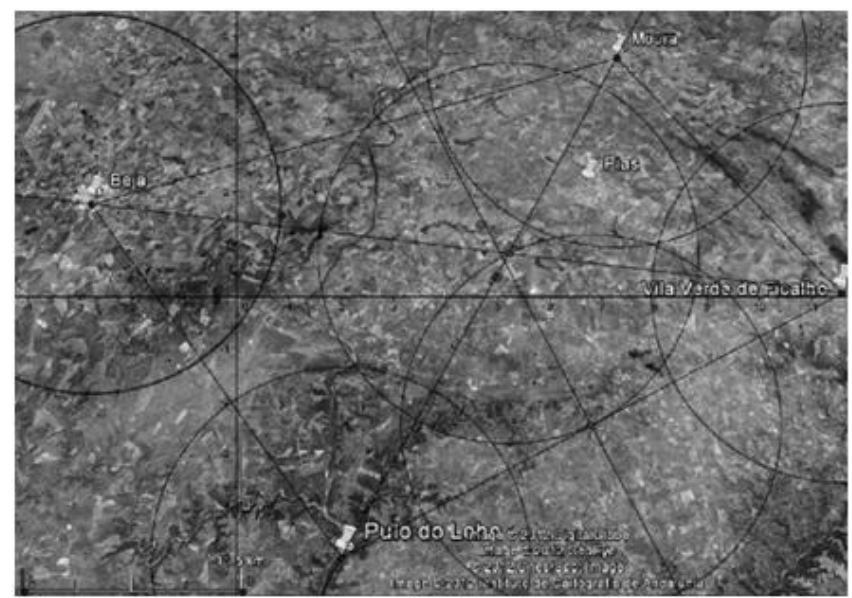

Fig. 1: Identification of places in order to implement infrastructures

\section{Disseminating Geo-Media Approaches to Teachers?}

The teachers involved have regular meetings, two hours every week, to prepare and decide the best ways to implement the Digital-Earth.eu project. The group integrates Mathematics and Geography teachers and we exchange information and best practices. We use web resources (Moodle, websites, Facebook, etc.) to promote the project, we attend the European Digital-Earth.eu meetings and we are integrated the "Teacher training" workgroup of the project. We also profit from teachers associations, such as the Portuguese Mathematics Association, to disseminate to teachers around the country. Right now we are focused on visiting other schools to present the project.

Innovative teaching approaches are key to keep up the motivation among teachers and students and being connected to the real world supporting growing knowledge. The DigitalEarth.eu project helps us to network at an international level as it allows us to keep up-todate and share ideas and information with others in the field.

\section{Conclusion}

Digital-Earth.eu activities provide students and teachers with a unique opportunity to improve teaching methods and activities, boosting motivation on both sides. Students are more eager to learn and explore real world problems and, thus, be able to develop their own knowledge, while teachers also have the possibility to learn and profit from the students achievements. 